\title{
CONSIDERAÇÕES SOBRE A FENOMENOLOGIA HERMENÊUTICA DE PAUL RICOEUR ${ }^{1}$
}

\author{
Antonio Vicente Marafioti GARNICA ${ }^{2}$
}

- RESUMO: O objetivo deste trabalho é tecer considerações sobre as bases teóricas da Fenomenologia Hermenêutica de Paul Ricoeur. Para isso, partimos do esboço de alguns aspectos da Fenomenologia em Heidegger e discutimos certas faces da distinção entre as concepções de Ricoeur e Heidegger quanto à fundamentação da Hermenêutica na Fenomenologia, trabalhando com a Fenomenologia Estrutural e a Fenomenologia Hermenêutica.

- UNITERMOS: Hermenêutica; fenomenologia.

\section{Introdução}

O presente trabalho tem por objetivo estudar elementos da Fenomenologia Hermenêutica de Paul Ricoeur, enquanto um pensar filosóficofundamental, com raízes nas Fenomenologias de Husserl e Heidegger e, em certa parte, nos trabalhos de Dilthey. Tais elementos são essenciais para um re-pensar da leitura enquanto ato consciente do leitor e, sendo assim, apontam para uma possibilidade de fundamentação teórica em trabalhos outros que tenham como objeto, por exemplo, a crítica literária, a análise de textos ou, em nosso caso específico, a possibilidade de interpretação em alguma particular esfera do pensamento científico.

Tratamos aqui, tão somente, de explicitar alguns aspectos das bases que sustentam o pensamento hermenêutico de Ricoeur. Para isso, entretanto, foi necessário buscarmos em Heidegger as bases de uma fenomenologia (já radicada em Husserl) e, a partir disso, incorporando aos poucos elementos outros pertencentes

1. O presente artigo foi primeiramente elaborado como parte das fundamentações teóricas para o trabalho "A interpretação e o fazer do professor: possibilidade do trabalho hermenêutico na Educação Matemática", apresentado ao Programa de Mestrado em Educação Matemática do Instituto de Geociências e Ciências Exatas da UNESP de Rio Claro. (Garnica, 1992).

2. Departamento de Matemática da Faculdade de Ciências - UNESP - 17033-360 - Bauru - SP. 
mais explicitamente à esfera da interpretação, estabelecer o exato ponto de ruptura entre fenomenologias, uma estrutural, outra hermenêutica: Heidegger e Ricoeur.

Sendo assim, este trabalho pode ser visto como um mero trabalho de sistematização, feito a partir de leituras e discussões de outros trabalhos. Posto que não buscamos originalidade ${ }^{3}$, o que se espera é que, na leitura desse nosso esforço de sistematização, possam ser encontrados motivos para perplexidades, até mesmo aquelas que indicarão a leitura dos textos originais, todos eles listados na bibliografia.

\title{
2. A fenomenologia em Heidegger
}

\author{
Segundo Heidegger (1989, p. 57)
}

a palavra 'fenomenologia' exprime uma máxima que se pode formular na expressão: 'às coisas em si mesmas!'- por oposição às construções soltas, às descobertas acidentais, à admissão de conceitos só aparentemente verificados, por oposição às pseudoquestões que se apresentam, muitas vezes, como 'problemas', ao longo de muitas gerações.

Para a investigação do termo 'fenomenologia' Heidegger volta às raízes gregas da palavra, uma "composição" de phainomenon ou phainestai e logos:

deve-se manter /.../ como significado da expressão 'fenômeno' o que se revela, o que se mostra em si mesmo. / .../ 'os fenômenos' constituem /.../ a totalidade do que está à luz do dia ou que se pode pôr à luz. (1989, p. 58);

Logos /... / é aquilo que é transmitido na fala, /.. / o sentido mais fundo de logos é deixar que algo apareça. (Palmer, 1986, p. 133)

O logos deixa e faz ver /.. / aquilo sobre o que se discorre e o faz para quem discorre /.../ e para todos aqueles que discursam com os outros. (1989, p.62-3)

Disso, a

combinação de phainestai e de logos, enquanto fenomenologia, significa deixar que as coisas se manifestem como são, sem que projetemos nelas as nossas próprias categorias. Significa uma inversão de orientação a que estamos acostumados; não somos nós que indicamos as coisas; são as coisas que se nos revelam. (Palmer, 1986, p.113)

Como as coisas se manifestam? O que significa manifestar-se, se fenômeno, como apresentado, é um mostrar-se, manifestar-se? Diz-nos Heidegger (1989, p. 59):

É muito corrente falarmos em manifestações de uma doença. O que se tem em mente são ocorrências que se manifestam no organismo, e ao se manifestarem, 'indicam' algo que em si 
mesmo não se mostra. O aparecimento dessas ocorrências, o seu mostrar-se, está ligado a percepções e distúrbios que em si mesmos não se mostram. Em conseqüência, manifestação enquanto manifestação de alguma coisa não diz um mostrar-se a si mesmo, mas um anunciar-se de algo que não se mostra. Manifestar-se é um não-mostrar-se. / .../ Assim quando se diz que com a palavra 'manifestação' indicamos algo em que alguma coisa se manifesta sem que seja em si mesmo uma manifestação, o conceito de fenômeno não é definido, mas pressuposto.

Fenômenos, portanto, não são manifestações, mas as manifestações, todas, dependem de um fenômeno. Além disso, o modo perspectival com que as coisas se nos revelam caracteriza a abordagem da fenomenologia do que se quer conhecer.

O método fenomenológico de abordagem é, então, dentro da fenomenologia, como primeiramente pensada por Husserl, um procurar conhecer algo pelo que desse algo se mostra, manifestando-se. A pesquisa, ela própria, enquanto um investigar de algo, é um mover-se em torno desse algo, procurando compreender, aos poucos, os aspectos que esse algo deixa que, dele próprio, sejam des-velados. O que percebemos, mesmo que perspectivalmente, são indicativos do que é, para nós, o que se procura conhecer. Daí a postura de um pesquisador ser sempre a postura de um "procurador" que não encontra definitivamente, mas que, na procura, compreende aspectos que, do que é pesquisado, se revelam.

Ao método fenomenológico, Heidegger se refere como sendo uma hermenêutica (Palmer, 1986), uma investigação do que, sendo-no-mundo, se manifesta; pois que o que se manifesta é compreendido/interpretado por aquele que é-no-mundo, sendo que, para Heidegger, por ter a fenomenologia do Dasein o caráter de hermeneuein (interpretar), "se tornam conhecidos ao Dasein, a estrutura de seu próprio ser e o significado autêntico do ser, dado na sua compreensão do ser. A fenomenologia do Dasein é hermenêutica no sentido original da palavra, que designava um trabalho de interpretação." (Palmer, p.134)

\section{A fenomenologia em Ricoeur}

Se a fenomenologia como dada em Heidegger tem um caráter hermenêutico, tal caráter é mais fortemente explicitado por Ricoeur que, seguindo Husserl, constrói uma Fenomenologia Hermenêutica, onde vai fundar seu projeto hermenêutico, a saber, a compreensão da própria existência.

Baseada no Lebenswelt (mundo-vida) de Husserl, a fenomenologia hermenêutica abre o campo do des-velar do que se pretende conhecer pelos intrincados caminhos da compreensão/interpretação, indicados pelas expressões. O desenvolvimento da filosofia de Ricoeur, segundo Ihde (1971), desemboca em duas grandes divisões: a fenomenologia estrutural, como dada por Husserl e Heidegger, e a fenomenologia hermenêutica, que se torna mais presente a partir de seu livro The symbolism of evil, sendo esse seu primeiro "exercício " numa fenomenologia hermenêutica. 


\title{
3.1 Fenomenologia estrutural e fenomenologia hermenêutica
}

A distinção entre a fenomenologia estrutural e a fenomenologia hermenêutica, segundo Ihde (1971, p.83), reside no fato de a primeira ser concernente às estruturas da experiência, e a segunda concernente às expressões; assim, o método, nessa reflexão (fenomenologia hermenêutica), é o enfoque na interpretação de expressões ao invés da interpretação de análises diretas da experiência.

\begin{abstract}
A hermenêutica pressupõe um texto ou uma expressão que tenha algo a dizer e que pode ser interpretado ou re-dito de outra maneira. Essa noção, que recai em dois dos significados clássicos do termo Hermenêutica - uma tradução, ou técnica de tradução para deixar expressões mais claras; e a exegese, que expõe o significado escondido de um texto - tem um objeto principal, o texto. Desse modo, um novo campo de inquérito aparece, o campo das expressões, uma 'linguagem'.
\end{abstract}

A imaginação desempenha papel fundamental na fenomenologia hermenêutica de Ricoeur, posto ter "a função de projeção e exploração no que diz respeito àquilo que é possível ao homem. Ela é, por excelência, a instituição e a constituição do que é humanamente possível. Imaginando suas potencialidades o homem exercita suas profecias a respeito da própria existência." (1971, p.88)

Nesse contexto, Ricoeur liga-se aos símbolos para procurar o que chama de "a plenitude da linguagem", rejeitando o modo idealístico - do idealismo alemão - de interpretação, que situa o EU fora do mundo. O movimento de buscar a interpretaçãc do que é dito ocorre no círculo hermenêutico onde o Eu está presente, imerso, compreendendo e explicando numa postura dialética tão poderosa que acaba por concretizar toda a dinâmica da interpretação.

A abordagem de Ricoeur para o estudo do símbolo é uma abordagem analítica ou seja, é uma análise profunda e minuciosa de como o símbolo ingressa na linguagem o que acaba por caracterizar o seu "caminho longo" para a hermenêutica:

Há duas maneiras de se fundamentar a hermenêutica na fenomenologia, /.../ a via curta é a de uma ontologia da compreensão, à maneira de Heidegger porque rompendo com os debates dı método, se aplica imediatamente no plano de uma ontologia do ser finito, para aí encontrar 1 compreender, já não como um modo de conhecimento, mas como um modo de ser. /... / A vii longa que proponho tem também como ambição levar a reflexão ao nível de uma ontologia mas fa-lo-á gradualmente, seguindo os requisitos sucessivos da semântica, depois da reflexão (1988, p. 8)

Se é suspeitando do simbólico que Ricoeur encontra a possibilidade de ingressa numa Hermenêutica, a questão da linguagem, começando com o símbolo, torna-se । centro de sua fenomenologia hermenêutica. Pela necessidade de compreender ex pressões simbólicas, na esfera da linguagem, Ricoeur considera que: 
1. O homem é linguagem e, assim, o problema da linguagem é o problema do sujeito humano. Abre-se, aqui, a questão do fator "contexto" na interpretação, levando à perspectiva da pertença do humano:

Eu pertenço à minha civilização do mesmo modo que estou cercado pelo meu corpo. Estou-nacivilização, e isto independe da minha história ou de meu corpo. (Ihde, 1971, p. 23)

2. A linguagem é "palavra" que revela, que leva do fechado à reflexão, é palavra que des-vela. A linguagem é o veículo do discurso, é a totalidade das palavras e suas significações onde o discurso humano internaliza o ser no mundo:

O que eu faço quando ensino? Eu falo. Não tenho outro meio de sustento nem outra dignidade; não tenho outro modo de transformar o mundo e nenhuma outra influência sobre os homens. A palavra é meu trabalho, a palavra é meu reino. (Ihde, 1971, p. 24)

Ricoeur (1988, p. 14-5) chama de símbolo

a toda estrutura de significação em que um sentido direto, primário, literal designa por acréscimo um outro sentido indireto, secundário, figurado, que apenas pode ser apreendido através do primeiro. Essa circunscrição das expressões com sentido duplo constitui, precisamente, o campo hermenêutico. /.../ a interpretação, diremos, é o trabalho do pensamento que consiste em decifrar o sentido escondido no sentido aparente, em desdobrar os níveis de significação literal; mantendo assim a referência inicial à exegese, isto é, à interpretação dos sentidos escondidos.

O símbolo assim tido é o que caracterizará a hermenêutica de Ricoeur, isto é, a hermenêutica definida pelo trabalho com o símbolo, considerando, fundamentalmente, a dimensão semântica desse símbolo.

\subsection{Do mundo-objeto ao mundo-linguagem: 'indireticidade', esforços e ingenuidades}

Se a fenomenologia hermenêutica de Ricoeur parte da desconfiança no símbolo para a compreensão da existência, é necessário que elementos da fenomenologia estrutural estejam presentes para que a experiência seja também investigada, porém indiretamente, ou seja, por sua expressão. Trata-se, pois, de optar por um mundo-linguagem em detrimento de um mundo-objeto, primeiramente perceptivo, da fenomenologia estrutural.

A fenomenologia estrutural reflete o sujeito por significados que podemos chamar de mundoobjeto. Na fenomenologia hermenêutica, este mundo-objeto é preterido a um mundo-linguagem. O mundo da expressão é agora o 'objeto' que é usado para 'refletir' o sujeito. (Ihde, 1971, p. 98) 
Desse modo, em Ricoeur, a linguagem é uma função mediatória entre a experiência (consciência de) e sua expressão. Assim, a relação entre experiência e expressão funciona na troca das estruturas experienciais para o campo lingüístico.

Sendo o objetivo compreender a experiência não diretamente, mas via-linguagem, a fenomenologia hermenêutica cria o que Ricoeur chama de ordem primeira e de ordem segunda de 'indireticidade'.

A ordem primeira de 'indireticidade' fica estabelecida quando o campo de trabalho é mudado; é a opção pela expressão. Desse modo, a experiência deve ser investigada por sua expressão. Nessa situação, a linguagem torna-se mediadora do movimento da experiência pré-lingüística - portanto, ainda não-elaborada, não discurso - para a expressão. Com isso, o modelo lingüístico da hermenêutica é um substituir de um campo de expressão para um campo que reflita a experiência.

Tendo saído do campo da experiência para o campo da expressão da experiência, a segunda ordem de 'indireticidade' ocorre dentro da esfera da linguagem, onde se dá a possibilidade da interpretação das expressões pela hermenêutica, com o objetivo de compreender a experiência. Essa é, também, a esfera da cultura e da história relacionadas com a interpretação do homem sobre si-mesmo e é, ainda, a esfera onde tem sentido trabalhar as relações do texto com o contexto, onde põe-se a questão da 'aplicação', dado que a hermenêutica não encara a tarefa da interpretação "como um mero esforço do arqueólogo que pretende penetrar num outro mundo, mas como uma tentativa de medir a diferença entre o texto e a situação atual. /. . / Por outras palavras: 'compreender um texto é sempre já aplicá-lo'." (Palmer, 1986, p.191)

Temos, então, que, num primeiro esforço, devemos sair da experiência para a linguagem. Esse esforço carrega uma primeira ingenuidade, onde se 'ouve' o dizer do texto na crença: acredita-se que. Essa primeira ingenuidade é transposta quando se tenta uma interpretação do dito no texto. No contexto hermenêutico pressupõe-se que a expressão tenha algo a dizer e o que é dito por ela deve ser ouvido e compreendido. Começa-se, assim, a penetrar na 'aura' do texto, ao invés de manter-se junto dele somente pela crença, embora a crença não deixe de ser uma maneira de compreensão do texto, porém não abrangente. Sair da imediaticidade da compreensão, isto é, da crença, é perder a primeira ingenuidade junto ao texto. A crença hermenêutica carrega, contudo, uma segunda ingenuidade, uma vez que a interpretação, na esfera da história e da cultura, propõe-se a examinar o 'arcaico', o dado passado, anterior, primeiro. Necessário é, para isso, que seja suplantada a distância temporal, atualizada na interpretação pela aplicação, conquanto se recupere a história do texto e do intérprete. Uma vantagem dessa segunda ingenuidade é que a natureza arcaica que precisa ser investigada para a recuperação da história previne qualquer crença na imediaticidade, ou seja, suprime a primeira ingenuidade.

Disso tudo, temos que o acesso à experiência só ocorre por intermediários onde o fundamental desses intermediários são os símbolos, parte constitutiva da linguagem, e 0 
Aqui, a primeira ordem de 'indireticidade' mostra-se mais clara: no plano lingüístico, o sentido e o vivido, obscuros (não apenas por estarem ligados ao emocional, mas também por serem equívocos em sua multiplicidade de significados), são expressos como equívocos. As expressões simbólicas são, no campo da linguagem, o que as emoções são no plano da experiência. A emoção é vã, pode ser re-lembrada mas não re-vivida. O símbolo, todavia, permanece.

Para lá da simples descrição fenomenológica do símbolo e da apropriação hermenêutica ou segunda imediatez, a filosofia reflexiva procura pensar a partir dos símbolos, respeitando seu enigma original (Ricoeur, 1988, p. VI)

Afirma-se, novamente, que deve haver um laço muito forte (Ihde refere-se a isomorfismo) entre experiência e expressão.

\subsection{O círculo hermenêutico}

Chamaremos, de acordo com Ricoeur, de primeiro círculo hermenêutico à relação experiência-expressão, e de segundo círculo hermenêutico à relação expressão-interpretação.

O primeiro círculo é superado pelo segundo, o que constitui o problema hermenêutico. /.. / Agora à experiência, assumida como tendo sido trazida para a expressão, segue a tematização da expressão como um estudo do homem enquanto linguagem. (Ihde, 1971, p. 98-9)

O que chamamos de círculo existencial hermenêutico, portanto, abarca a idéia dos dois círculos acima explicitados. O círculo hermenêutico é nitidamente dialético, sendo tal dialética apontada mais claramente quando Ricoeur trabalha duas atitudes, tomadas pelo leitor, frente a um texto: a explicação e a compreensão.

\subsubsection{A dialética na Hermenêutica de Ricoeur: atitudes frente a um texto}

Frente a um texto, duas atitudes fundamentais podem ser assumidas: uma, de explicação; outra, de compreensão (Ricoeur, 1986). A Hermenêutica é, então, um jogo entre essas duas atitudes. Explica-se: se frente a um texto nos dedicarmos a colocá-lo em suspenso, tratando-o como dado pelo mundo do autor, estaremos preocupados com o interno ao texto. Podemos assim enfocar partes constitutivas desse texto, entrando em sua estrutura: 
Com efeito, é possível tratar os textos segundo as regras de explicação que a lingüística aplica /.../. Este modelo estrutural é que fornece o tipo de comportamento explicativo que aplicamos (na análise estrutural) aos textos. (Ricoeur, 1986, p. 146-7)

A esta postura chamaremos 'explicativa', enquanto, ao colocarmos o texto em suspenso, tratando de transformá-lo em palavra atual, viva, isto é, interpretar tal texto interpretando-nos, agora na esfera da história e da cultura, na 'aplicação' anteriormente discutida, estaremos numa postura que chamaremos 'compreensão'. A aparente dicotomia explicação-compreensão é discutida, primeiramente, em Dilthey (1833-1911), onde se afirma que a explicação é o modelo de inteligibilidade das ciências da natureza e a interpretação, uma forma derivada da compreensão, fundamentalmente ligada às ciências do espírito (as Geisteswissenschaften). Tal discussão, entretanto, não é aqui nosso objetivo, pois enveredaríamos por questões concernentes à tentativa de Dilthey em encontrar uma base metodológica para as Geisteswissenschaften, tendo a hermenêutica como fundante. Este, no entanto, é um ponto fundamental para que se compreenda a diferença entre as hermenêuticas de Heidegger e Ricoeur.

Heidegger trabalha hermeneuticamente quando constrói sua ontologia, mantendo um equilíbrio entre compreensão e interpretação, onde, ao falarmos em compreensão - existenciália do ser - há sempre uma interpretação espreitando (1982, Secção 32). Ricoeur introduz a explicação nesse binômio compreensão-interpretação. A inspiração para a inserção da explicação nesse binômio ele busca em Dilthey, mas destitui dessa explicação seu caráter causal (das ciências naturais), ele a amplia numa dialética que, com a compreensão-interpretação, acaba por fundar sua Hermenêutica e indica, já, um distanciamento inicial com a Hermenêutica Heideggeriana.

Como dar um organon à exegese, isto é, à inteligência dos textos? Como arbitrar as ciências históricas face às ciências da natureza? Como arbitrar o conflito de interpretações rivais? /.../ [a hermenêutica de Heidegger] não é destinada a resolvê-los, mas a dissolvê-los; tanto mais que Heidegger não quis considerar nenhum problema particular a respeito de tal ou tal ente: ele quis reeducar nosso olhar e reorientar o nosso olhar, ele quis que subordinássemos o conhecimento histórico à compreensão ontológica. (Ricoeur, 1988, p. 12)

e por iniciar seu trabalho hermenêutico propondo também uma ontologia da compreensão, como Heidegger:

Se começo por este acto de eqüidade em relação à filosofia de Heidegger, é porque não a considero uma solução adversa /... / A dúvida que exprimo no termo deste parágrafo incide apenas sobre a possibilidade de fazer uma ontologia directa, imediatamente subtraída a toda exigência metodológica /.../ Mas é o desejo desta ontologia que move o empreendimento aqui proposto. (Ricoeur, 1988, p. 8)

Voltemos ao ponto em que Ricoeur trabalha a dialética entre a compreensão e a explicação: propõe-se que a dicotomia 'aparente' entre explicação e compreensão 
seja resolvida não por distinções, mas por uma "fina dialética" entre essas duas atitudes. (1986, p. 162)

Esta dialética é vista como um jogo de focos entre a análise estrutural do texto e a ampliação dessa análise, na posterior interpretação. Não se trata de termos explicação e interpretação como distintas e estanques:

Por dialética entendo a consideração de que explicar e compreender não constituem os pólos de uma relação de exclusão, mas de momentos relativos de um processo complexo que podemos chamar interpretação /.../, ao invés de considerar uma exclusão mútua entre essas duas atitudes, a questão será abordada por uma concepção mais dialética, de uma interpenetração entre essas atitudes: a compreensão é chamada explicação se não mais existe a situação de diálogo /.../. Numa simples situação de diálogo, explicar e compreender se acham muito próximas. Quando não se compreende espontaneamente, uma explicação será necessária; tal explicação fará com que minha compreensão seja melhorada. (1986, p. 162-5)

Tal dialética trata, portanto, da própria interpretação: interpretar passa a ser o jogo dialético entre a análise estrutural do texto e a compreensão deste texto. Conseqüentemente, a atitude explicativa, na interpretação, é necessária como mediadora, mesmo sendo destruidora da compreensão intersubjetiva; dada a ausência do diálogo. Tal mediação, porém, é "exigida pelo próprio discurso, pois é o discurso que pede esse processo sempre mais complicado de exteriorização do si-mesmo /.../" (1986, p. 166) e "Finalmente, a correlação entre explicação e compreensão e vice-versa, constitui o círculo hermenêutico." (1986, p. 211), onde ocorre o movimento interpretativo.

\section{Notas}

3. Tal alerta torna-se necessário face o dito por Montaigne: "Há mais afã em interpretar as interpretações do que em interpretar as coisas, e mais livros sobre livros do que sobre outro assunto: Tudo formiga de comentários, de autores mesmo, há grande carência." E o de Pascal: "Alguns autores, quando falam de seus trabalhos, dizem: 'meu livro, meu comentário, minha história, etc.' Eles fedem como burgueses bem estabelecidos, sempre com a sua 'propriedade privada' na boca. Melhor seria se falassem: 'nosso livro, nosso comentário, nossa história, etc.' , pois nisso tudo há mais riqueza dos outros do que sua." (citados por Roberto Romano In: Antonio Candido, 1990, p. 124). 
IARNICA, A. V. M. Some remarks on Ricoeur's Hermeneutics Phenomenology. Trans/Form/ Ação, São Paulo, v. 16, p. 43-52, 1993.

- ABSTRACT: This paper presents remarks on the basis of Ricoeur's Hermeneutics Phenomenology. To achieve this, it begins by examining aspects of Heidegger's Phenomenology and focusing on aspects of the distinction between Structural and Hermeneutic Phenomenologies, that is, on Heidegger's and Ricoeur's conceptions of Hermeneutics founded in Phenomenology.

- KEYWORDS: Hermeneutics; phenomenology.

\section{Referências bibliográficas}

ANTONIO CANDIDO. A interpretação. In: COLÓOUIO DA UNIVERSIDADE ESTADUAL DO RIO DE JANEIRO, 2., 1990. Rio de Janeiro, 1990.

GARNICA, A.V.M. A interpretação e o fazer do professor: possibilidade do trabalho hermenêutico na Educação Matemática. Rio Claro, 1992. Dissertação (Mestrado) - Instituto de Geociências e Ciências Exatas, Universidade Estadual Paulista.

HEIDEGGER, M. Ser e tempo. Trad. Márcia S. Cavalcante. Petrópolis: Vozes, 1989. 2v.

IHDE, D. Hermeneutic Phenomenology: the philosophy of Paul Ricoeur. Evanston: North-Western University, 1971.

PALMER, R. Hermenêutica. Trad. Maria Luiza Ribeiro Ferreira. Lisboa: Ed. 70, 1986. 284p.

RICOEUR, P. O conflito das interpretações: ensaios de hermenêutica. Trad. M.F. Sá Correia. Porto: Rés, 1988. 487p. . Du texte à l'áction: essais d' hermeneutique II. Paris: Denil, 1986. 406p.

\section{Bibliografia}

BICUDO, M.A.V. Possibilidade de compreender-se o conhecimento matemático segundo a abordagem Heideggeniana. Rio Claro: UNESP, s. d. (mimeografado)

CENTRO DE ESTUDOS FENOMENOLÓGICOS DE SÃO PAULO. Vida e Morte: ensaios fenomenológicos. São Paulo: Companhia Ilimitada, 1988. 150p.

ESPÓSITO, V. H. C. Hermenêutica: estudo introdutório. São Paulo: Sociedade de Estudos $\epsilon$ Pesquisa Qualitativos, 1990. 28p. (mimeografado)

HOWARD, R.J. Three faces of hermeneutics: an introduction to current' theories of understanding. California: University of California, 1982. 187p.

MARTINS, J., BICUDO, M.A.V. Estudos sobre existencialismo, fenomenologia e educação São Paulo: Moraes, 1983. 80p.

RICOEUR, P. O conflito das interpretações: ensaios de hermenêutica. Trad. Hilton Japiassu Rio de Janeiro: Imago, 1978. 419p. O discurso da ação. Trad. Artur Morão. Lisboa: Ed. 70 1988, 156p. Teoria da interpretação. Trad. Artur Morão. Lisboa: Ed. 70, 1987. 109p. 